\title{
A Blockchain Platform for the Supportive Exchange of Data, Goods and Services
}

\author{
Rita Pizzi \\ Department of Computer Science \\ University of Milan \\ Milan, Italy
}

\begin{abstract}
Universal access to information and knowledge is the basic condition for improving the quality of life in developing countries.

Nowadays the sharing of information is made easier by the evolution and diffusion of Information and Communication Technologies (ICTs).

In this framework a web-based platform, the World Food Security E-Center (WFSEC), was developed by the University of Milan with the goal of fighting food emergencies by transferring competences and adequate solutions to rural communities.

In addition, we designed a blockchain structure for the WFSEC in order to allow a controlled exchange of the IoT data and to obtain a self-financing network by the exchange of tickets as electronic money.
\end{abstract}

\section{Keywords}

Teleconsulting, agrifood, cooperation, IoT, blockchain.

\section{INTRODUCTION}

The global connectivity and the cell/smartphone large diffusion allows to offer better life conditions for disadvantaged people and communities [1].

Driven by the urgent humanitarian needs highlighted by the OCCAM Observatory of Digital Communications and the Infopoverty Program (http://occam.org), the University of Milan realized the World Food Security E-Center, devoted to assist developing countries on rural development and urban nutrition, sharing knowledge and adequate solutions.

The software platform exists also as a Telemedicine service in the frame of the Program "Milan in the fight against hunger, malnutrition and related diseases" supported by the Municipality of Milan, serving as a consulting tool and health information exchange [2][3]. Telemedicine can be added in the future as further service of the integrated platform [4][5].

\section{THE TELECONSULTING PLATFORM}

The platform can be accessed after registration by Service Users (SU) and Service Providers (SP). The SU is the subject located in the developing country that collects data, images, signals manually or through IoT sensors located on the territory.

The SP is usually a University, research center or specialized laboratory that offers consultancies addressing the problems raised by SU (Figure 1).

\author{
Letizia Oreni \\ 'L. Sacco' Department of Biomedical and Clinical \\ Sciences \\ University of Milan \\ Milan, Italy
}

The whole platform is coordinated by the WFSEC Hub manager, that can control the correct addressing and finalization of all the information transactions (Figure 2).

In particular, all the SU and the SP have the possibility to:

- view the global, personal and group activity stream, post directly their questions or sending a short message to other users;

- request or provide information, submit files or view the published ones [6] (Figure 3);

- provide courses uploading documents, images and links to videos, and attend them [7] (Figure 4);

- get or add contact infos of the SU or SP subscribed to the platform (Figure 5);

- manage or join a real time multiuser VOIP videoconference [8] (Figure 6);

- connect to a suitable channel for transmission of the Internet of Things signals coming from suitable sensors installed in the developing countries, yielding useful real time data (Figure 7);

- query the data repository to access all the data and the published information, and create reports and statistics [9][10] (Figure 8).

The online platform, as well as all the generated documents, can be accessed from PCs as well as from mobile phones, both on-line and off-line, providing a synchronous and asynchronous information exchange.

After the necessary testing phase and the involvement of a group of experts and laboratories, the platform is ready to be immediately available to all the users in the need of remote assistance.

\section{IoT / BLOCKCHAIN EVOLUTION OF THE PLATFORM}

We also studied a blockchain framework that applied to the WFSEC would be able to allow both the controlled and supportive management of the supplied data (especially IoT data) and the self-sustainability of the platform.

Blockchain is a network protocol that uses various technologies to create a chain of linked blocks. This chain is owned by all the nodes of the network and acts as a distributed database that allows the shared control of all transactions on an equal basis [11].

As for the above described platform configuration, we have so far two types of subjects: the SU and the SP.

At the core of this structure we have the Hub, central body that acts as guarantor for the whole network. 


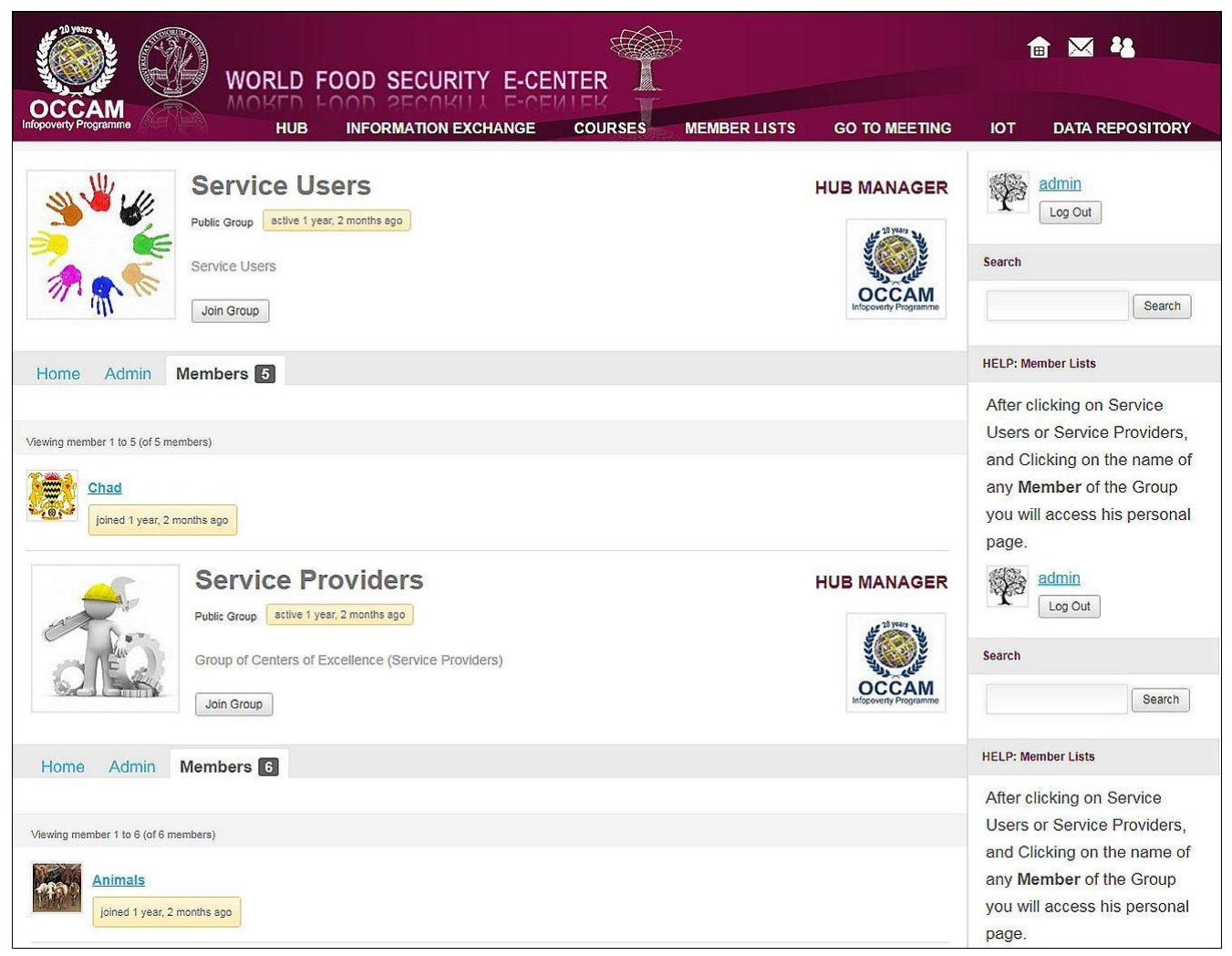

Fig 1: Service Users and Service Providers list

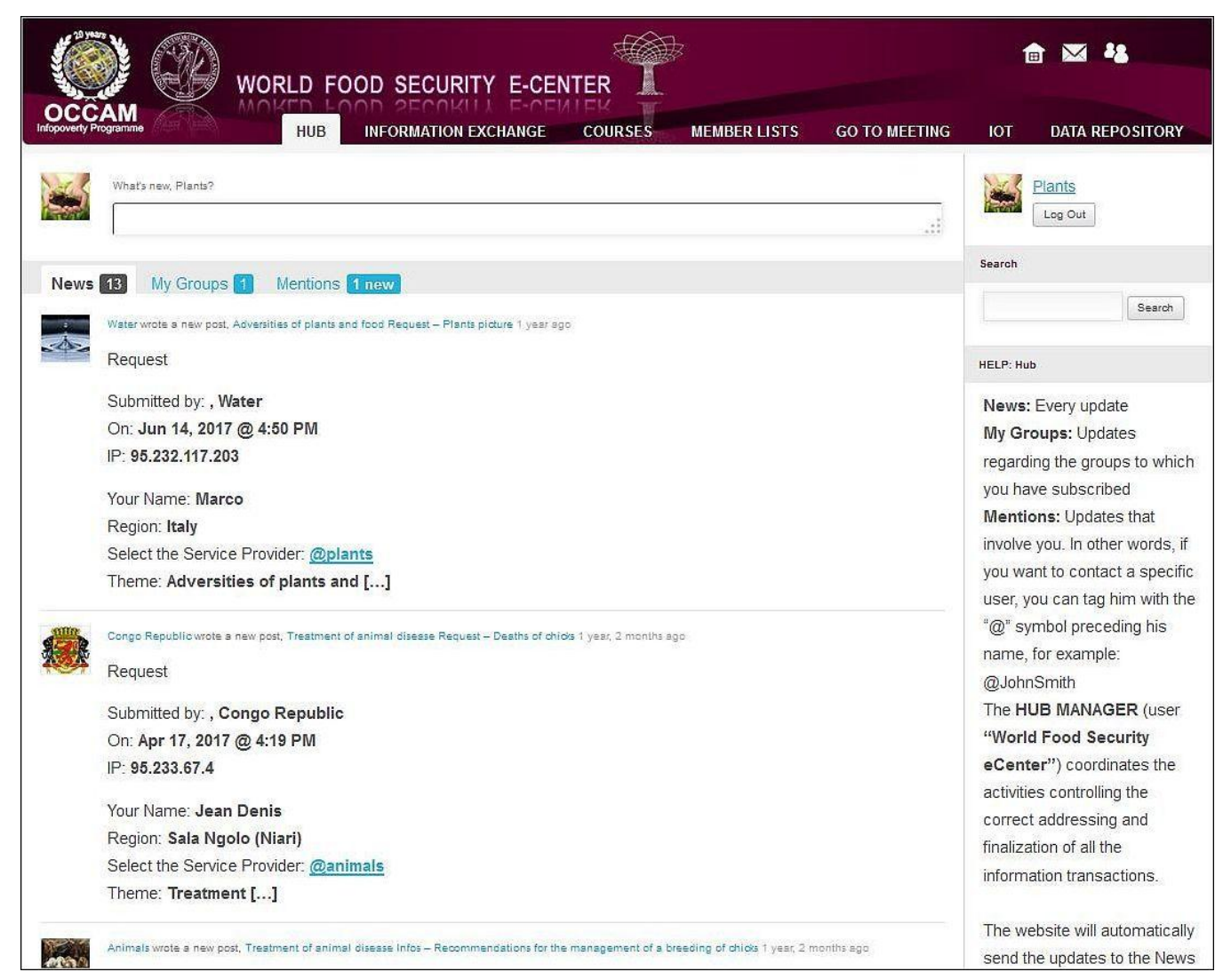

Fig 2: The Hub manager log allows to control the flow of all the platform transactions 


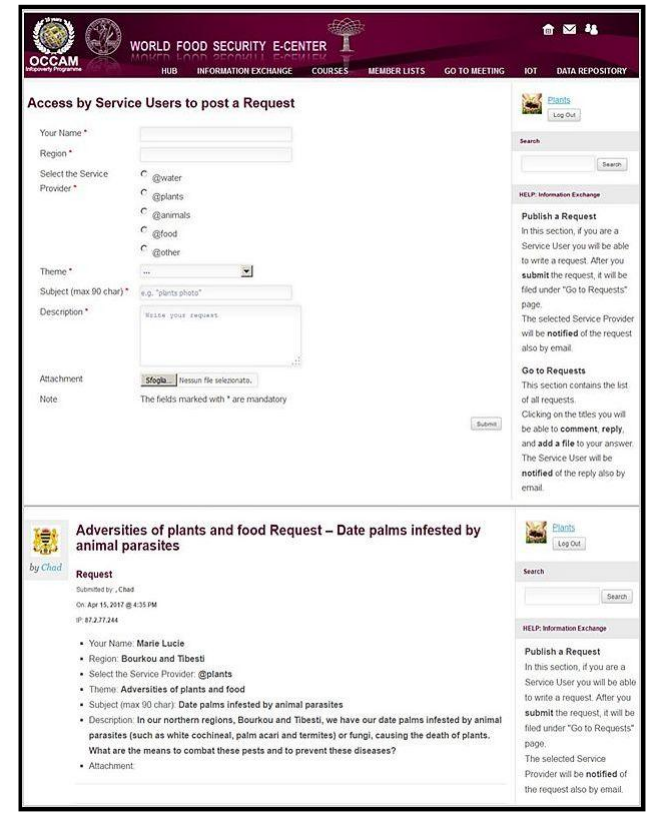

Fig 3: Posting of a Service User's requests

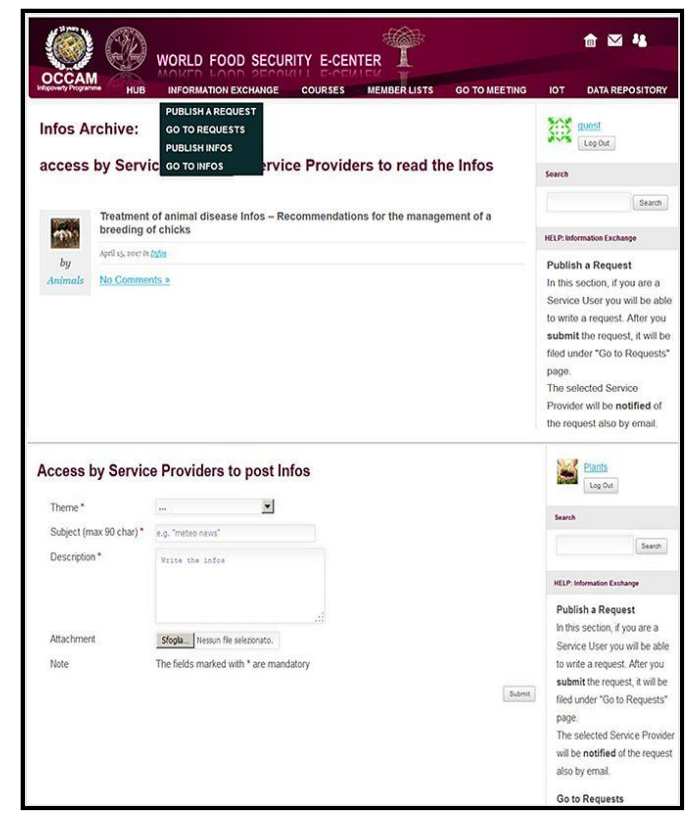

Fig 5: A menu allows Service Providers to post Infos or to answer the received requests

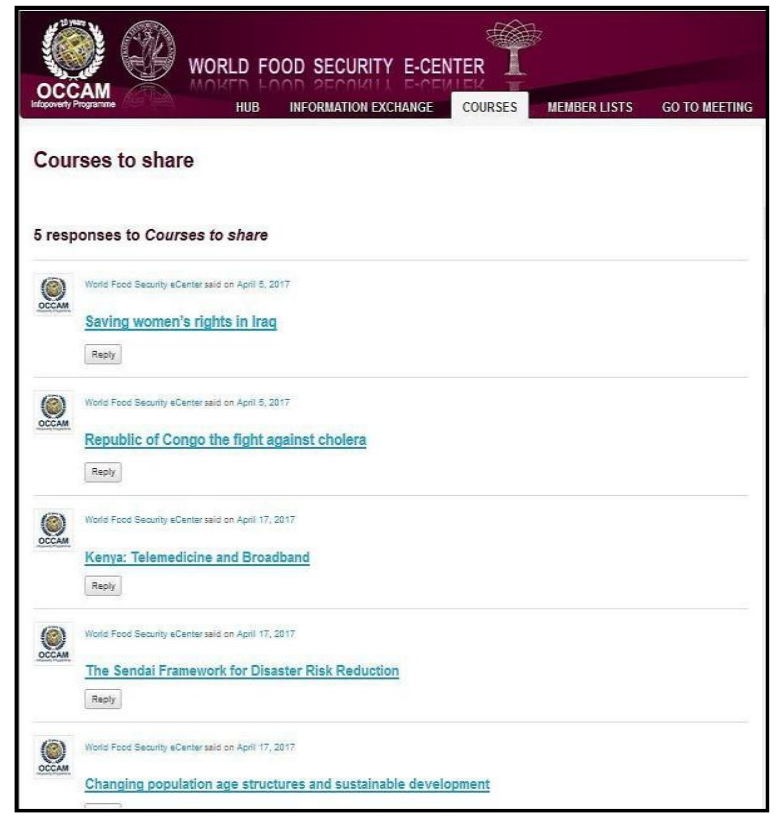

Fig 4: Available Courses

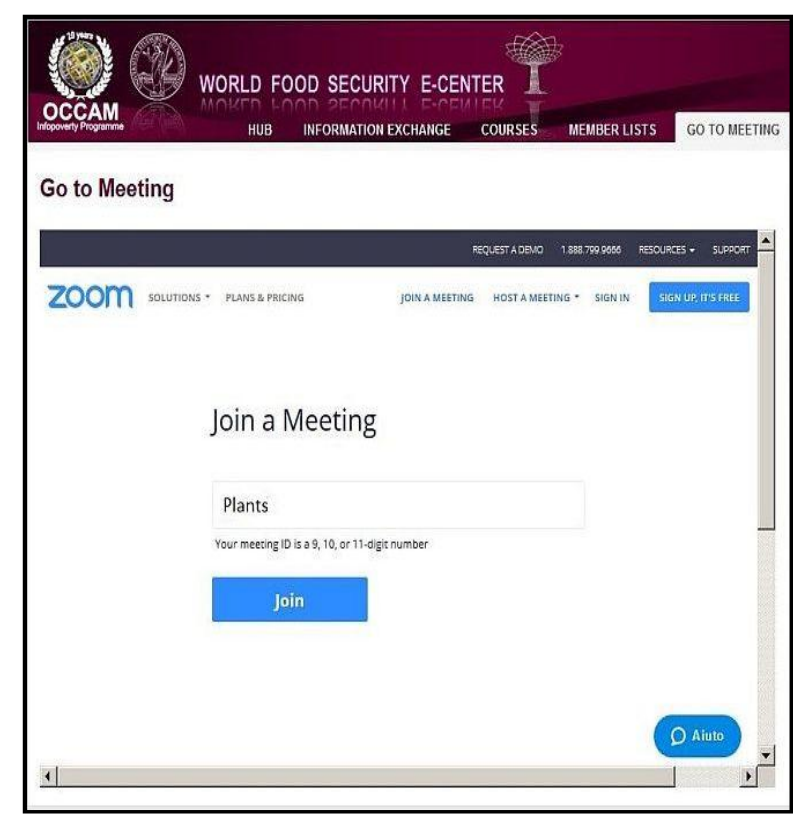

Fig 6: Videoconference access page 


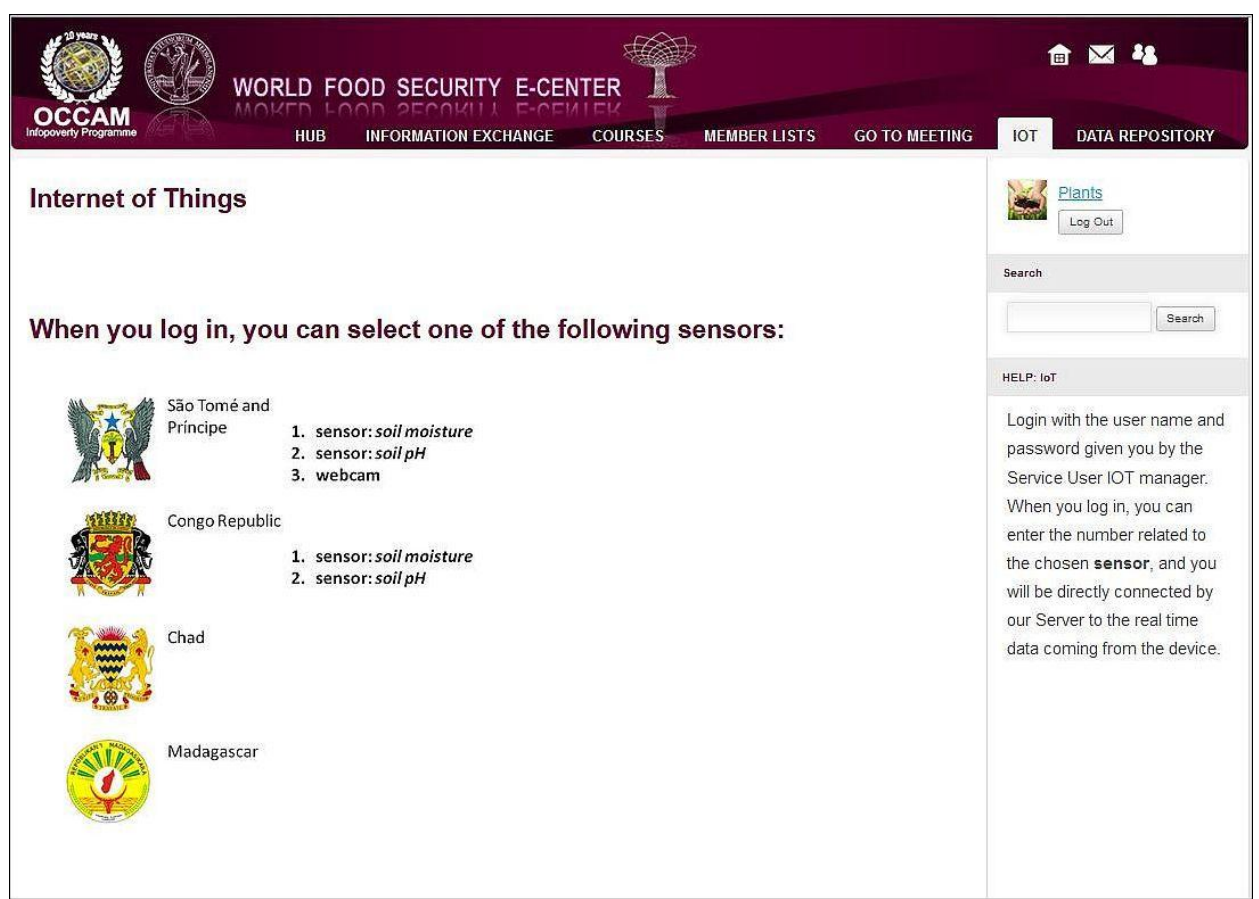

Fig 7: IoT channels. Data from sensors located on the Service Users territories are directly received by the platform server

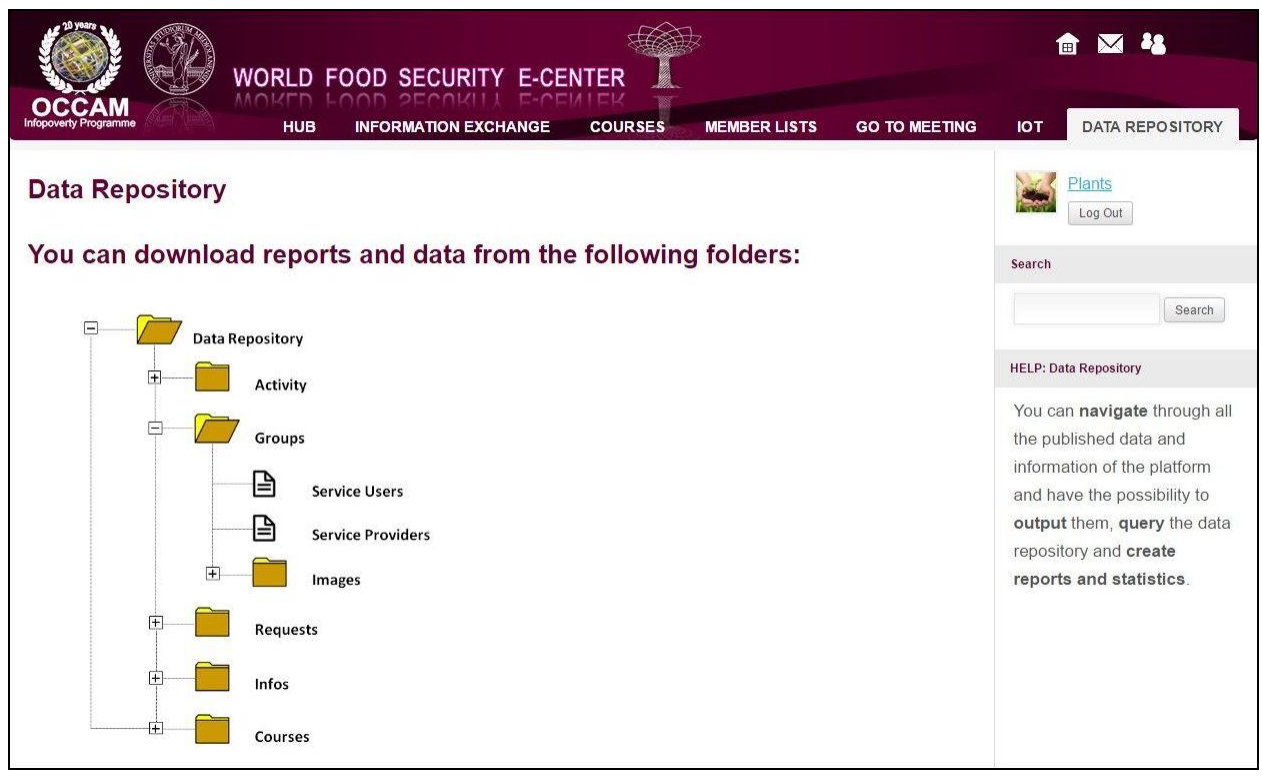

Fig 8: Data repository

The new scenario prefigures a private blockchain platform in which not only data and information, but tickets that act as electronic money are exchanged [12].

The Hub has the task of verifying the correct occurrence of the exchange of tickets for the payment of the consultancies.

The novelty lies in the possibility to reach a self-financing network [13].

But it is also possible the introduction of new intermediate subjects, the Stakeholders ( $\mathrm{SH})$.
The infrastructure at the base of the network remains the same.

The Stakeholders (that can be also the Service Users selling their products) offer services and goods on the network, for them they require compensation. This fee is partly turned over to the Hub. The Hub then checks the amount of tickets present on the whole network and decides in which percentage to increase this number.

After which the costs paid to the relative Stakeholders are reversed, with the addition of a premium proportional to the paid tickets (Figure 9). 


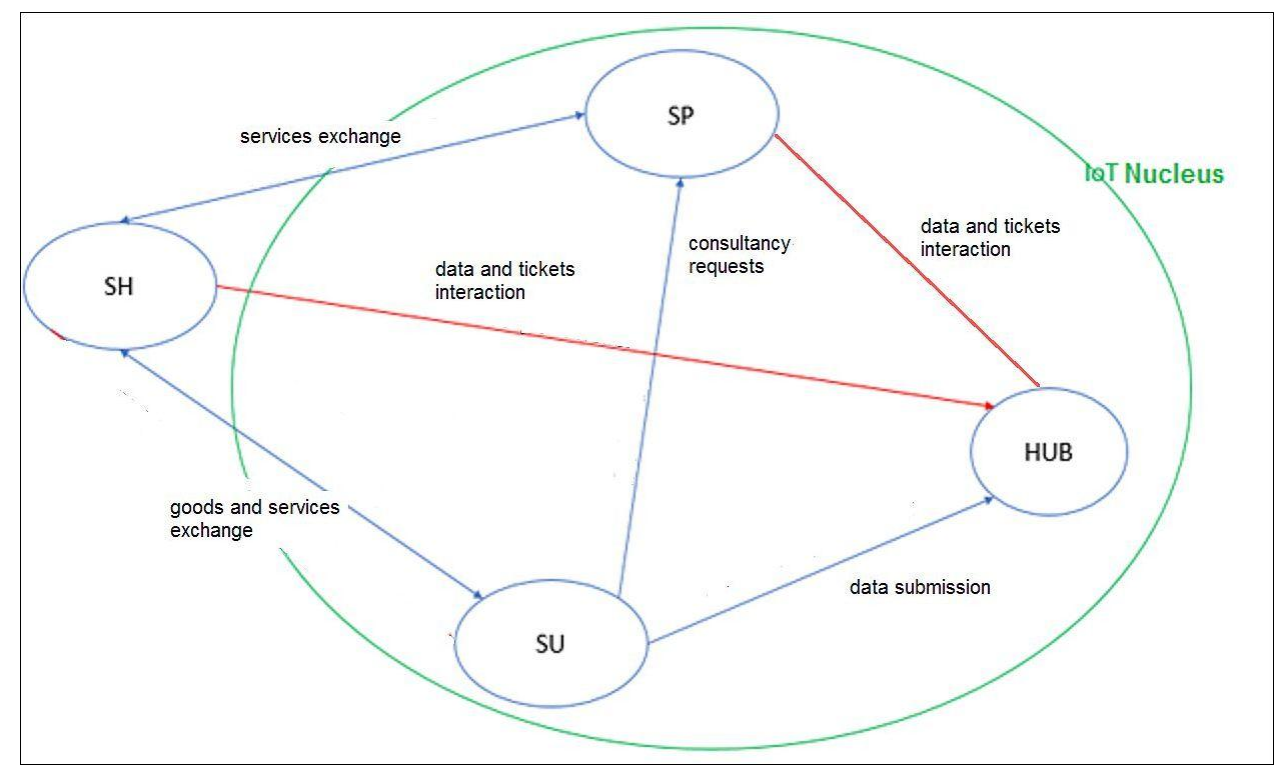

Fig 9: Evolution of the platform: Blockchain tickets exchange

These awards allow services and goods to be more accessible as costs decrease, or the provider can get the resources necessary to improve the service/good offered.

The software platform maintains the same architecture, but the request form becomes for example as in Figure 10.

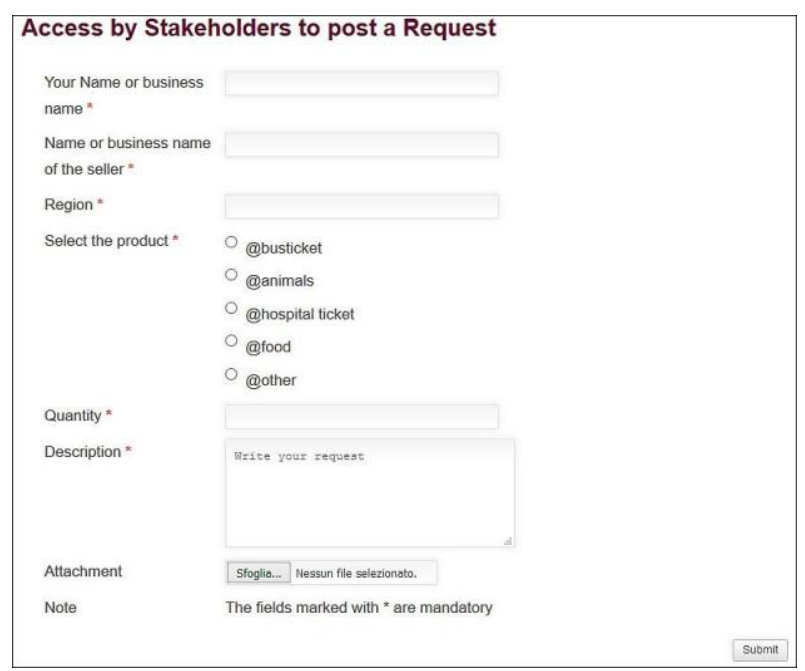

Fig 10: New request form including exchange of good and services to be paid through Blockchain

There are other advantages offered by the blockchain framework:

- in the IoTs network, the blockchain itself allows to guarantee and authenticate the data exchanged between smart devices;

- the blockchain could also act as guarantor for the exchange of renewable energies between individuals without consulting a centralized intermediary;

- it also allows point-to-point control of donations, as the blockchain itself guarantees that the transactions reach the correct target without intermediate manipulations.

In summary the data exchange supported by the teleconsulting platform activates a self-controlled ticket movement [14]. The virtual money can be exchanged with regular currency, but has the advantage not to face currency exchange problems among countries, allowing simpler product selling procedures.

The blockchain platform extends the application context to the whole world, allowing the exchange of any kind of good and services, included data and knowledge, by means of the exchange of tickets passing through the Hub [15]. Thus any Service User can benefit from the platform usage.

\section{CONCLUSIONS}

We developed a web-based platform able to support farming communities in the developing country by means of a network of experts. The knowledge can be shared and remains at disposal for future needs, increasing in time. The platform can be accessed from any device and can manage data coming from remote IoT sensors.

Blockchain technology may be applied to the web platform in such a way as to allow agrifood operators in remote countries to exchange not only knowledge but also goods and services in a supportive framework [16] [17]. A central Hub acts as a guarantor and shares awards among all the users allowing an easier access to services and goods. In the meantime, the underlying teleconsulting platform allows the agrifood operators to access high-level knowledge to improve their work [18].

The model can be easily implemented and would allow the self-sustainability of the platform.

\section{ACKNOWLEDGMENTS}

The authors wish to thank the OCCAM Observatory of Digital Communications for yielding the opportunity and the framework to develop the platform. They are also indebted to Dr F. Iacoppi (Department of Computer Science, University of Milan) for his fundamental contribution to the study of the presented blockchain model.

\section{REFERENCES}

[1] Italian association for solidarity among peoples (AISPO) 2012. Congo: Telemedicine and Distance Learning at Fomulac Hospital.

http://aispo.org/en/progetti/congo-telemedicine-anddistance-learning-in-the-fomulac-hospital-of-katana-inthe-south-kivu-region/ 
[2] Pizzi, R., Oreni, L., Grassi, S., Ridolfo, A.L., Rusconi, S. and Galli, M. 2014. Telemedicine for Africa: Remote Consulting to Support the Fight against HIV/AIDS in Swaziland. In Proceedings of the $3^{\text {rd }}$ Int Conf on Circuits Systems Communications Computers and Applications (Nov. 2014), 62-67.

[3] Pizzi, R., Oreni, L., Grassi, S., Ridolfo, A.L., Rusconi, S., Croce, F. and Galli, M. 2015. Telemedicine for Africa: collaborative action between Italy and Swaziland against HIV infection. International Journal of Biology and Biomedical Engineering. ISSN: 1998-4510, 9, 90-97.

[4] Karaolis, N., Jackson, D., Ashworth, A., Sanders, D., Sogaula, N., McCoy, D., Chopra, M. and Schofield, C. 2007. WHO guidelines for severe malnutrition: are they feasible in rural African hospitals?. Arch Dis Child, Vol. 92, 3, 198-204.

[5] Wamala, D.S. and Augustine, K. 2013. A meta-analysis of telemedicine success in Africa. J Pathol Inform., 4, 6.

[6] WordPress.org 2014. Form Manager.

https://wordpress.org/plugins/wordpress-form-manager/

[7] WordPress.org 2014. Course Manager.

https://wordpress.org/plugins/wp-course-manager/

[8] Suduc, A.M., Bîzoi, M. and Filip, F.G. 2009. Exploring Multimedia Web Conferencing. Informatica Economică, Vol. 13, 3, 5-17.

[9] Microsoft TechNet 2005. SQL Server 2005 Reporting Services (SSRS)

http://technet.microsoft.com/en-us/library/cc917530.aspx

[10] Microsoft 2014. Design a form template based on a Microsoft SQL Server database.

http://office.microsoft.com/en-us/infopath-help/design-aformtemplate-based-on-a-microsoft-sql-server-databaseHP010086639.aspx

[11] United Nations World Food Programme 2017. What is 'blockchain' and how is it connected to fighting hunger?. World Food Programme Insight (Mar. 2017). https://insight.wfp.org/what-is-blockchain-and-how-is-itconnected-to-fighting-hunger-7f1b42da9fe

[12] Bhaskar, N.D. and Chuen, D.L.K. 2015. Handbook of Digital Currency. Academic Press. ISBN 9780128021170, 45-65.

[13] Chen, K., Stegerean, R. and Nistor, R.L. 2017. A Modern Management Approach in Internet Era. In Proceedings of the $11^{\text {th }}$ International Management Conference (Nov. 2017), 918-927.

[14] Tapscott, D. and Tapscott, A. 2016. The Blockchain Revolution: How the Technology Behind Bitcoin is Changing Money, Business, and the World. Portfolio ISBN: 978-0-670-06997-2.

[15] Marr, B. 2016. How Blockchain Technology Could Change The World. Forbes (May 2016).

https://www.forbes.com/sites/bernardmarr/2016/05/27/h ow-blockchain-technology-could-change-theworld/\#2bee9c62725b

[16] iAfrikan News 2016. Senegal To Introduce A New Blockchain-Based National Digital Currency, The Second Such Currency In The World. iAfrikan (Nov. 2016).

https://www.iafrikan.com/2016/11/24/senegal-tointroduce-a-new-blockchain-based-national-digitalcurrency-making-it-only-the-second-country-to-have-anational-digital-currency/

[17] EconoTimes 2016. Tunisia To Replace eDinar With Blockchain-Based Currency. EconoTimes (Jan. 2016).

http://www.econotimes.com/Tunisia-To-ReplaceeDinar-With-Blockchain-Based-Currency-140836

[18] Toprak, E. and Genc-Kumtepe, E. 2014. Cross-Cultura Communication and Collaboration: Case of an International e-Learning Project. European Journal of Open, Distance and e-Learning.

http://www.eurodl.org/?p=archives\&year $=2014 \&$ halfy ear $=1$ \& article $=618$ 